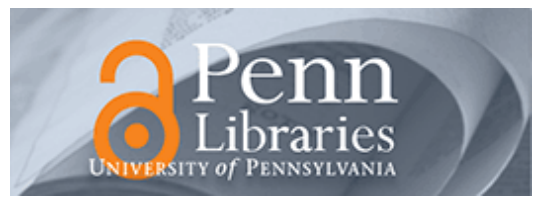

University of Pennsylvania ScholarlyCommons

6-1980

\title{
Television Sponsorship Forms and Program Subject Matter
}

Joseph Turow

University of Pennsylvania, jturow@asc.upenn.edu

Follow this and additional works at: https://repository.upenn.edu/asc_papers

Part of the Advertising and Promotion Management Commons, Broadcast and Video Studies Commons, and the Public Relations and Advertising Commons

\section{Recommended Citation}

Turow, J. (1980). Television Sponsorship Forms and Program Subject Matter. Journal of Broadcasting, 24 (3), 381-397. https://doi.org/10.1080/08838158009363993

At the time of publication, author Joseph Turow was affiliated with Purdue University. Currently, he is a faculty member in the Annenberg School for Communication at the University of Pennsylvania.

This paper is posted at ScholarlyCommons. https://repository.upenn.edu/asc_papers/395

For more information, please contact repository@pobox.upenn.edu. 


\section{Television Sponsorship Forms and Program Subject Matter}

\section{Disciplines}

Advertising and Promotion Management | Broadcast and Video Studies | Communication | Public Relations and Advertising

\section{Comments}

At the time of publication, author Joseph Turow was affiliated with Purdue University. Currently, he is a faculty member in the Annenberg School for Communication at the University of Pennsylvania. 


\section{Television Sponsorship Forms and Program Subject Matter}

JOSEPH TUROW

\section{Introduction}

A growing body of literature on the factors that shape the production and distribution of commercial television content emphasizes the strong influence of sponsorship upon the nature of programs that are produced and televised. ${ }^{1}$ Among the most systematic attempts to track this influence are those by broadcast historian Erik Barnouw and economist William Melody. Barnouw, recognizing advertisers as television's dominant patrons, calls the commercial TV sponsor a "potentate of our time" and observes that "a vast television industry has grown up and around the needs and wishes of sponsors.", He notes that advertisers and broadcasters desire to air programs that draw large numbers of viewers who conform to various social categories (demographics) which predict their strong interest in the products being advertised. Melody argues that "the fundamental economic exchanges in broadcast markets take place between the market manager (network or station) and the advertiser .... The interests of the viewing audience are satisfied only when they happen to correspond with the interests of the advertiser."3

Barnouw, Melody and others are persuasive in their analyses of the extent to which, and the manner in which, the advertiser/market-manager relationship plays a crucial role in shaping the program schedule. At the same time, such examinations contain an important limitation to understanding the association between sponsorship and programming. In discussing the consequences of the basic advertiser/market-manager relationship for programming, they do not differentiate between the three major kinds of support that exist within the confines of that relationship on American television-full sponsorship (where one or more advertisers associate themselves completely with a show and pay the network for the show's entire time period every time it is broadcast), participating sponsorship (where advertisers do not maintain continuing association with a show and instead buy from the network commercial spots between segments of particular program episodes), and sustaining sponsorship (where the network supports a program while not expecting or finding advertisers for it). In failing to scrutinize the link between each sponsorship form and programming, these writings ignore the possibility that the different sponsorship forms in and of themselves influence the production and televising of different kinds of programs. Such a possibility does not hold theoretical interest alone. If high association can be found between sponsorship forms and particular forms of programming, and if there is reason to believe this would continue to be the case, one might conclude that a way to encourage a desired mix of programming within the existing American commercial television complex would be to encourage (or require) a certain mix of sponsorship forms.

The purpose of this study is to begin to explore this possibility, through an examination of the historical link between sponsorship forms and subject matter in children's series. The analysis will show that simple associations of sponsorship form and subject matter were not consistent during the three decades of commercial children's television. Rather, the findings point toward a more complex pattern: Sponsorship forms that were most common during a particular decade tended to lean toward common kinds of subject matter more than did the sponsorships that were not in the majority. At the same time, sponsorship forms that were not the most common in a particular decade tended more towards unusual subject matter than did the form that was most common. The results do not encourage those who hope that a mix of traditional sponsorship forms could be used to bring about a desired mix of subjects on children's television. The results do, however, suggest a novel perspective on the meaning of sponsorship forms within the television industry and point toward areas for further research.

\section{Some Preliminary Considerations}


It is difficult to develop formal hypotheses about the relationship between sponsorship forms and subject matter, since very little systematic research relates to the concerns of organizations managing different sponsorship forms within the same commercial system. Writings on inter-organizational relations, both in and out of the mass media, do emphasize the importance of external financial support for the activities of the organization. For example, Evan ${ }^{4}$ predicts an organization managing or producing goods will change its products in response to significantly changed goals of organizations that purchase substantial amounts of those products. A relevant corollary of this prediction runs as follows: If the television networks and their advertisers consistently associate different programs or audience goals with the different sponsorship forms, the networks will telecast different kinds of programs to match those different support forms.

Unfortunately, the small amount of literature that bears on television does not facilitate the direct testing of this prediction. The researchers who deal with the topic of sponsorship forms are unclear-and perhaps conflicting - on whether the goals of patrons with respect to different sponsorship forms are consistently and significantly different enough to bring about different shows. For example, Melody, in an historical and contemporary overview of support for children's television, implies that they are not and that a general, though changing, programming philosophy not responsive to specific sponsorship forms has guided the advertiser/market manager relationship through the decades of commercial television. ${ }^{5}$ Barnouw seems to disagree, implying that full sponsorship, participation, and network-sustained support have been associated strongly with different program and audience goals by the patrons. Full sponsors, Barnouw implies, are likelier than participating advertisers to choose programs reflecting their corporate image and philosophy. He contends that networks are more willing to experiment with unusual material in programs they know will be sustaining than in those expected to carry their weight in advertising. ${ }^{6}$

Because Barnouw and Melody do not make their positions on sponsorship forms explicit, and because of the difficulty of establishing how the differences Barnouw implies affect programming, this study could not derive specific predictions from these writings. However, Barnouw and Melody do point the way toward an important area of research, and a more general hypothesis that different forms of support associated with different kinds of subject matter can be explored. Such an investigation can aid in developing more specific hypotheses about the association of sponsorship forms with TV content and in conducting research on the organizational relationship between sponsorship forms and programming.

Accordingly, the decision was made to track the existence of sponsorship forms in a particular area of television programming from its commercial beginnings (1948) through 1978, and to compare the association of those forms with subject matter during the three decades. Children's television was selected because the issue of sponsorship in programs oriented to children has increasingly become a subject of controversy during the past several years. The use of advertising to support programs designed for youngsters has come under attack, not only for selling products but also for the narrow range of predictable programming that use of the home tube as a child marketplace has spawned. ${ }^{7}$ Certainly, as Melody has pointed out, ${ }^{8}$ advertisers' desire for high ratings and their interest in reaching specific age groups within the child audience have helped guide program decisions over the years. The purpose of this research was to determine whether another consideration in the advertiser/market manager relationshipthe selection of a sponsorship form-has been associated in a consistent manner with the use of particular subject matter in children's series. The intention here was to broach the possibility that one way to encourage a desired mix of children's programming within the existing commercial system would be to encourage (or require) a certain mix of sponsorship forms.

\section{Method}

For this study, children's programs were designated as those programs which the three major commercial networks (ABC, CBS, and NBC) themselves designated as children's shows during the years 1948 through 1978. ${ }^{9}$ This information was obtained from two sources-Anthony Maltese's thorough catalog of network children's fare (covering 1948-1964) ${ }^{10}$ and Nielsen rating reports on network programs (available beginning the 1958 volume). ${ }^{11}$ Maltese considered a program as a children's show if network files and publicity releases indicated it was produced especially for youngsters 12 years old or 
under. In Nielsen rating reports, specific classification codes, chosen by the networks, indicate children's fare. The fact that no contradictions appeared between the Maltese and Nielsen sources for the overlapping years (1958-1964) lends confidence to the reliability and validity of the sources.

Both the Maltese catalog and the Nielsen ratings disclosed the types of sponsorship that the programs had over the years. Information on various aspects of the programs' content was obtained from Maltese's work, from Vincent Terrace's Complete Encyclopedia of Television Programs, from Nina Davis' annual listing of television show, ${ }^{12}$ from TV Guide, and from The New York Times. For this study, three aspects of subject matter were of interest: 1) The main subject of the show-whether it was essentially fiction, non-fiction, or involved performing activities (such as child sports, competitive games, or music appreciation); 2) The fantasy-reality orientation of the show-whether the program was mostly within the realm of possibility by contemporary standards (reality), whether it was mostly outside the realm of possibility (fantasy), or whether it straddled the realm of possibility (well-mixed); ${ }^{13}$ and 3 ) The format of the show-whether the program was presented fully or partially on film, in a non-studio format, or whether the program took place in a studio (a talk show, demonstration show, studio drama, quiz show, variety show, etc.). These aspects of subject matter are often areas of concern in the ongoing debate about children's television. Public pressure groups regularly urge more programs involving non-fiction or performing activities, reality rather than fantasy, and a variation of program formats beyond the exclusive use of film. ${ }^{14}$

In order to get a detailed view of continuity and change in support for children's television, the various sponsorship forms for children's shows were first displayed in two-year periods, from 1948 through 1978, with 1978 standing alone. The 31 years were subsequently arranged into three decades, with the last "decade" having 11 years. The number of programs included in each decade equalled the number of different shows telecast during those years; a program lasting more than one year counted only once during the decade. Changes in main subject, fantasy/reality orientation, and format were charted over those decades, as were changes in the presence of full, participating, and sustaining sponsors. Associations between subject and sponsorship over the three decades were then examined.

\section{Findings}

Table I displays the various sponsorship forms for children's series by two year periods. It indicates that the number of shows fluctuated substantially over the 31 years, from a low of 10 in 1948-49 to a high of 62 in 1972-73. The 1970s tended to have the largest number of shows, while the 1960s tended to have the smallest number. The table also shows substantial changes in the types of support provided to juvenile series over 31 years. Sustaining support was dominant in the first four years, after which full sponsorship was the most common type through 1964-65. In 1956-57, participation overtook sustaining support as the second most common form of sponsorship. However, it was not until 1970-71, that participation became overwhelmingly dominant, encompassing $70 \%$ (later, over $80 \%$ ) of the programs. The remaining fully sponsored shows during the 1970s were mostly short "information spots," such as "In the News," that were scattered throughout the Sunday morning and Saturday children's schedule. Sustaining programs were virtually non-existent in the 1970s; one of the few was "Marshall Ephron's Illustrated, Simplified, and Painless Sunday School" (CBS, 1974-75 and 1976-77). 


\begin{tabular}{|c|c|c|c|c|c|c|c|c|c|c|c|c|c|c|c|c|c|}
\hline \multicolumn{18}{|c|}{ TABLE I: What Was The Form of Sponsorship? } \\
\hline & $48-49$ & $50-51$ & $52-53$ & $54-55$ & $56-57$ & $58-59$ & $60-61$ & $62-63$ & $64-65$ & $66-67$ & $68-69$ & $70-71$ & $72-73$ & $74-75$ & $76-77$ & \multicolumn{2}{|c|}{78 TOTAL PGMS } \\
\hline & $\mathrm{N}=10$ & $\mathrm{~N}=52$ & $\mathrm{~N}=46$ & $\mathrm{~N}=41$ & $\mathrm{~N}=41$ & $\mathrm{~N}=28$ & $\mathrm{~N}=31$ & $\mathrm{~N}=29$ & $\mathrm{~N}=34$ & $\mathrm{~N}=37$ & $\mathrm{~N}=49$ & $\mathrm{~N}=58$ & $\mathrm{~N}=62$ & $\mathrm{~N}=55$ & $\mathrm{~N}=56$ & $\mathrm{~N}=42$ & $\mathrm{~N}=405$ \\
\hline & $\%$ & $\%$ & $\%$ & $\%$ & $\%$ & $\%$ & $\%$ & $\%$ & $\%$ & $\%$ & $\%$ & $\%$ & $\%$ & $\%$ & $\%$ & $\%$ & $\%$ \\
\hline Full & 10 & 39 & 51 & 51 & 50 & 59 & 61 & 59 & 50 & 22 & 4 & 3 & 5 & 3 & 4 & 5 & 24 \\
\hline Participating & 20 & 10 & 6 & 14 & 21 & 21 & 23 & 21 & 21 & 19 & 31 & 73 & 83 & 84 & 87 & 91 & 51 \\
\hline Sustaining & 20 & 37 & 30 & 23 & 17 & 10 & 3 & 3 & 3 & 3 & -- & 2 & -- & 2 & 2 & -- & 12 \\
\hline Sustaining, then full & 30 & 12 & 6 & 5 & 7 & 3 & 3 & 3 & 3 & -- & - & -- & 2 & -- & -- & -- & 2 \\
\hline Sustaining \& Participating & 10 & 4 & 4 & 5 & 2 & - & - & 6 & - & -- & - & - & -- & -- & -- & -- & 1 \\
\hline Full, then participating & -- & -- & -- & -- & -- & - & - & -- & 6 & 3 & 6 & 5 & 2 & -- & -- & -- & 1 \\
\hline Cosponsor & -- & -- & -- & -- & - & - & - & 6 & 6 & 32 & 31 & -- & -- & -- & -- & -- & 5 \\
\hline Cosponsor, then participating & 10 & -- & -- & -- & -- & - & - & -- & -- & 8 & 16 & 9 & 5 & 2 & 2 & -- & 2 \\
\hline \multirow[t]{2}{*}{ Other } & -- & -- & 2 & 2 & 2 & 7 & 7 & 12 & 9 & 14 & 12 & 9 & 5 & 6 & 6 & 5 & 2 \\
\hline & 100 & 101 & 99 & 100 & 99 & 100 & 97 & 100 & 98 & 101 & 100 & 100 & 102 & 97 & 101 & 101 & 100 \\
\hline
\end{tabular}

Drawing from several sources regarding adult-oriented as well as child oriented television, ${ }^{15}$ it is possible to offer several reasons for these dramatic shifts in the support forms of children's television. During the first decade of commercial television, the networks were anxious to promote their new medium and presented programs even when they could not find advertisers for them. As an increasing percentage of American households bought TV sets, however, advertising money became increasingly available to support virtually the entire broadcast day, and sustaining programs became much rarer. Advertisers, for their part, initially viewed their financial role in television as they had viewed it in radio-as fully supporting and identifying with individual series. By the 1960s, however, the high cost of television programming and the desire of many advertisers to forego the advantage of identifying with particular shows for the benefit of spreading their commercials across many programs in the network schedules encouraged the tremendous growth of participating sponsorship, and the decline of full sponsorship.

Interestingly, a type of support existed in the 1960s that served as a transition between the domination of fare by full sponsorship in the 1950s and the domination of fare by participating sponsorship in the 1970s. Called "co-sponsorship," it involved a decision by one advertiser to assume partial financial responsibility for a show (similar to full sponsorship) as well as an attempt by the advertiser or network to secure additional commercials for particular episodes from other advertisers (a move similar to participation). ${ }^{16}$ In the late $1960 \mathrm{~s}$, a substantial number of programs were co-sponsored. In fact, during that period, co-sponsorship surpassed full sponsorship as the most common form of program support. It gave way to participation abruptly in the 1970s.

Table I also shows that during the years when the popularity of one form was giving away to another, some programs actually switched sponsorship forms. Programs tended to move from sustaining to full or participating sponsorship in the early 1950s, from full to participating or co-sponsorship during the late 1960s, and from co-sponsorship to participation in the late 1960s and early 1970s. It is important to note that programs were coded in only one way throughout their existence; a program that changed sponsorship was designated as changing throughout its existence. For example, a show lasted ten years and switched from full to participating support in its second year was listed as "full to participating" for all 10 years. Consequently, some shows are listed for several years under categories that denote change in sponsorship. Actually, however, only $8 \%$ (32) of the 405 children's programs made changes in sponsorship from 1948 through 1978, as the last column in Table I indicates.

\section{Sponsorship and Subject Matter}

In charting the association between sponsorship and subject matter over the years, it is useful to focus on programs that were backed by either full, participating, or sustaining support- that is, by one of the forms that endured through three decades of commercial television. There were 351 such programs; they comprised $87 \%$ of the total number of shows produced for children from 1948 through 1978. The 
heading across Table II presents the number of programs by decades and the distribution of sponsorship types by decades. The general pattern is the same as the one seen in Table I. A greater number of shows (109 versus 74) appeared in the first decade (1948-1957) than in the second (1958-67), with the third decade (1968-78) having the greatest number of all (190). Full sponsorship was the most important support form during the first and second decades. However, the number of fully sponsored programs did decline from 54 in the 1948-57 period to 44 in 1958-67, and then plunged to seven shows in the 1968-78 period. Sustaining programs, second in prominence with 40 shows in the first decade, fell to a far third afterward with seven in the second decade and two in the third. Participating shows, by contrast, increased in prominence, from 15 shows (and third place) in the first decade, to 23 shows (and second place) in the second decade, to an overwhelming first place (181) shows in the third decade.

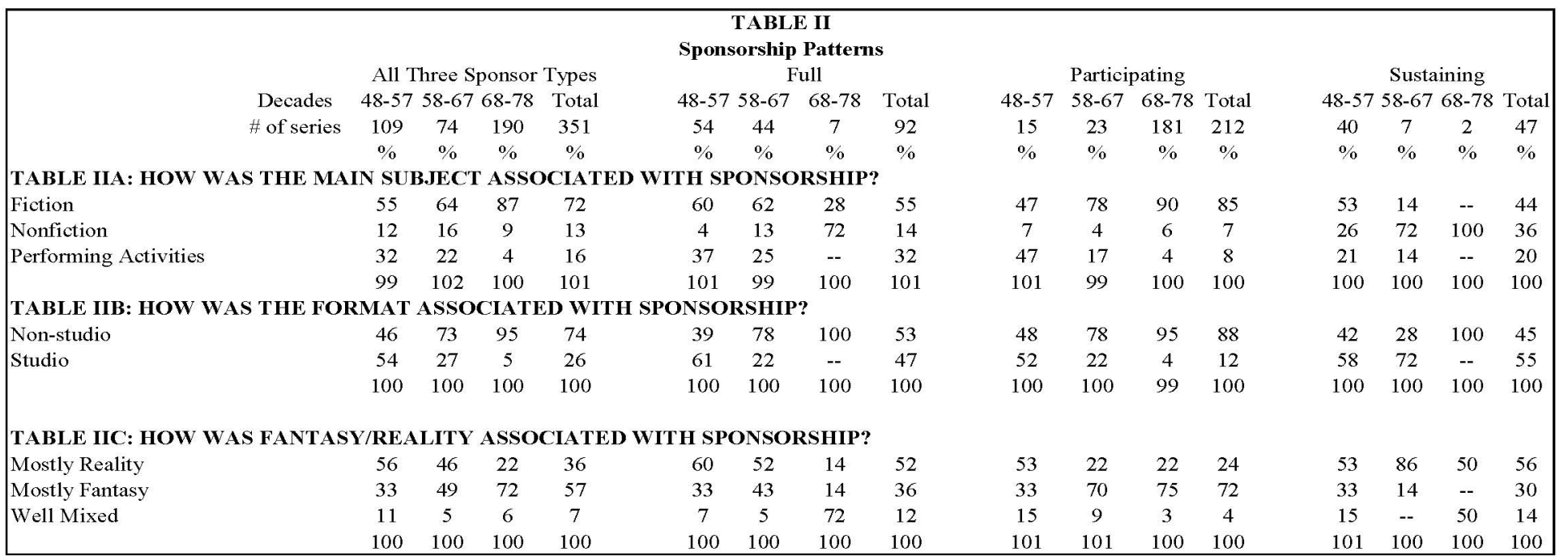

General data on subject matter is noted in Column A of Table II. The tables show that the categories of subject matter which described the majority of content ("the norms") were often quite clear and predictable. The main subject of the programs during each decade tended to be fiction. Fiction characterized 55\% of the shows in the first decade, $64 \%$ in the second decade, and $87 \%$ during the last 11 years. The steady increase in the proportion of fiction programs was accompanied by a decrease in the percentage of nonfiction programs and an even greater decrease in programs revolving about performing activities. The format of the programs evidenced a different pattern: Table IIB shows that in the first decade programs taking place wholly in a studio outnumbered those with non-studio segments. However, in 1956-1967 and 1968-1978 a non-studio format was the norm. That format increased sharply in prominence, from $46 \%$ in the first decade to $73 \%$ in the second decade, to $95 \%$ in the third decade. By contrast, studio-based formats decreased in prominence sharply across the decade. The norm for fantasyreality orientation also changed over time. Column A of Table IIC indicates that $56 \%$ of the programs had a "reality orientation" during the first decade, while only $22 \%$ were characterized that way in the third decade. During the third decade fantasy was the norm; it comprised $72 \%$ of the shows. The second decade, in contrast to the others, was a period of balance between programs that had fantasy orientations (46\% of the total) and programs that were reality-based (49\% of the total).

Thus far the discussion has dealt with subject matter. At this point, questions regarding the link of subject matter to sponsorship will be asked: Was one form of sponsorship most highly associated with certain subject matter across decades? And, more generally, was one form of sponsorship most highly associated with normative subject matter, or unusual subject matter, across the decades?

To answer the first question directly, only a weak association was found. Tables IIA, IIB and IIC do show sponsorship forms to be consistently associated with two subject categories. Participating sponsorship had the strongest link to fantasy series in every decade; $33 \%$ of participating programs in the first decade, $70 \%$ in the second decade; and $75 \%$ in the third decade were fantasy. In addition, sustaining 
support had the strongest association with non-fiction; $26 \%$ of the sustaining shows in the first decade, $72 \%$ in the second, and $100 \%$ in the third decade were non-fiction. By and large, however, such links were not the rule. No consistently high association could be found in the tables between any sponsorship form and fiction, performing activities, reality orientation, mixture or orientations, studio format, or nonstudio format.

The answer relating to normative and unusual programming is more complex. Generally, whether sustaining, participating, or full sponsorship devoted a greater percentage of its programming than did others to a normative or to an unusual subject area depended on the decade. No consistently highest association between sponsorship and normative subject matter across decades could be found; only one such association with unusual subject matter-the association between sustaining support and nonfiction-could be seen. Careful examination of Table II indicates, however, that a rather pervasive pattern associating subject and sponsorship was in evidence: Sponsorship forms that were most common during a particular decade tended to lean more toward normative programming than did the sponsorships that were not in the majority. At the same time, sponsorship forms that were not the most common in a particular decade tended to lean more toward unusual programming than did the form that was the most common.

While the data did not conform to this pattern perfectly, the associations did follow the pattern most of the time. For example, full sponsorship was most common in the first decade. In that decade, the percentage of fully sponsored programs that supported the norms-fictional, reality-oriented programming in a studio setting - was greater than the percentage of participating or sustaining programs that supported those categories. At the same time, the two sponsorship forms not in the majority leaned toward other types of content: The percentages of participating programs involving performing activities $(47 \%)$ and a non-studio format (48\%), and the percentage of sustaining programs that were non-fiction $(26 \%)$, were substantially higher than the percentages of fully sponsored shows involving such subject matter. Participation and sustaining support also surpassed full sponsorship in the percentage of programs with a mixture of reality and fantasy (15\% to $7 \%)$.

Some deviation from the pattern appeared during the second decade. For one thing, although full sponsorship was still in the majority and fiction was still the norm, the percentage of fully sponsored series that were fiction programs $(62 \%)$ was exceeded by the percentage of participation programs that presented fictional fare $(78 \%)$. Also, the percentage of fully sponsored programs conforming to the norm of a non-studio format (78\%) was matched by participation. Nevertheless, some aspects of the pattern were seen clearly, particularly those relating to sponsorship forms not in the majority. For example, sustaining support was again most highly associated with non-fiction. Although that form was most highly linked with non-fiction throughout all three decades, the decrease in the number of sustaining shows from 40 to seven from the first to the second decade was associated with an increase in the percentage of sustaining shows that were nonfiction from $26 \%$ to $72 \%$. A much higher percentage of sustaining programs than other programs $(72 \%)$ was also associated with the non-studio format in the second decade.

In the third decade, the pattern of sponsorship regarding majority and minority support was more clearly seen. Participation was the major sponsorship form, and its percentage of two norms-fiction and fantasy programming-exceeded those of sustaining and participating sponsorship. There was one deviation regarding a third norm: In the case of the non-studio format, $95 \%$ of the participating programs fit that category while $100 \%$ of the less common sponsorships-sustaining and full-also conformed to the norm. In other areas, though, fully sponsored and sustaining programs fit the pattern. Both of the two sustaining shows and 72\% (5) of the fully sponsored shows were non-fiction; $72 \%$ (5) of the fully sponsored shows and 50\% (1) of the sustaining shows were mixtures of fantasy and reality; and 50\% (1) of the sustaining shows has a reality orientation.

As the numbers in the previous paragraph indicate, a higher percentage of unusual subject matter associated with a sponsorship form that was in the minority often indicated very few programs. Sometimes, in fact, a small percentage of the majority sponsorship form represented the same, or a greater number of unusual programs as did a higher percentage of a less prominent sponsorship form. For 
example, the $72 \%$ of the seven fully sponsored programs in the third decade that were nonfiction represented five series while the $6 \%$ of the 181 participating programs in the third decade that were nonfiction represented 11 shows. Nevertheless, focusing on percentages is crucial to testing the basic hypothesis of this study: To uphold the prediction that particular sponsorship forms associate with particular kinds of subject matter, the percentage of fully sponsored non-fiction shows should remain roughly the same irrespective of the number of programs supported for the form. This study has, however, shown little direct relationship between sponsorship form and subject matter. Indeed, an inverse relationship between unusual subject matter and prominence of sponsorship form tended to hold. The above case illustrates the pattern: When full sponsorship was the majority sponsor during the first and second decades, its percentage of non-fiction programs was $4 \%$ and $13 \%$ respectively, as compared to $72 \%$ in the third decade. Similar examples can be found throughout Table II.

\section{Concluding Remarks}

This paper has charted the changes in various sponsorship forms during three decades of commercial television. Four major forms have been noted-full sponsorship, participation, cosponsorship, and sustaining support-and their use has changed over time. An examination has been conducted of the association of the three enduring sponsorship forms (full, participating, and sustaining) with certain fundamental aspects of subject matter. Contrary to what some writings on sponsorship might suggest, there were few consistent associations between specific forms of support and specific subject areas across three decades. Sustaining support was more highly associated with nonfiction, and participation was more highly associated with fantasy, than was any other kind of sponsorship. Generally, however, findings pointed toward a different, more pervasive pattern: Sponsorship forms that were most common during a particular decade tended to lean toward common kinds of subject matter more than did the sponsorships that were not in the majority. At the same time, sponsorship forms that were not the most common in a particular decade tended to lean more toward unusual programming than did the form that was most common.

It is possible that attention to other aspects of children's series would reveal a different pattern of association of programming with sponsorship forms; more research is needed on this score. At the same time, the categories of subject matter used in this study have been important in the public debate about children's television. Consequently, some of the findings of the investigation do suggest avenues for public policy consideration, particularly from the viewpoint of those who would like to inject more programming that has traditionally been unusual (such as non-fiction, reality-oriented, studio-based programming) into children's TV. For example, the data suggest that simply requiring certain forms of sponsorship will not guarantee certain kinds of programming. The evidence that mode of sponsorship has been less important in encouraging unusual fare than has that of a particular support form is in the minority. Perhaps the reason for this phenomenon is that by virtue of being in the minority, sponsorship which is in the minority calls attention to itself, both inside and outside the television industry. It is possible that when production personnel and network officials are involved with a form of program support that draws public or industry attention, a self-awareness that occurs encourages them toward some innovation or unusualness in the shows connected to that support. Conversely, when production and network personnel are involved with a sponsorship type not in the spotlight, the routines and pressures of programming override impulses to diverge from the norm. If this explanation is true, it follows that one way to induce the unusual in programming is to encourage intense critical interest on the part of the public — adults and children — regarding all types and techniques of program support.

The necessarily speculative nature of the last suggestion emphasizes how little is known about the specific consequences 'of sponsorship for usual and unusual programming. It would be interesting to determine if the patterns uncovered in this study of children's television are also evident in' more general television programming. It would be important to explore the goals and activities of those who manage sponsorship forms in network and advertising organizations to see if this paper's explanation for the patterns that were discovered can be supported. Generally, a creative and varied course of research must 
be carried out before the influence of sponsorship forms upon the televised messages that reach the public can be fully understood.

${ }^{1}$ See, for example, Paul Hirsch, "Processing Fads and Fashions: An Organization-Set Analysis of Cultural Industry Systems," American Journal of Sociology, 77:639-659 (Spring, 1972); Gaye Tuchman, "Introduction," in Gaye Tuchman, ed.; The TV Establishment, (Englewood Cliffs, New Jersey: Prentice-Hall, 1974); Paul DiMaggio and Paul Hirsch, "Production Organizations in the Arts," American Behavioral Scientist, 19:735-752 (Summer, 1976); and Diana Crane, "Reward Systems in Art, Science, and Religion," American Behavioral Scientist, 19:719-733. (Summer, 1976).

${ }^{2}$ Erik Barnouw, The Sponsor: Notes on a Modern Potentate, (New York: Oxford University Press, 1978), p. 4.

${ }^{3}$ William Melody, Children's Television: The Economics of Exploitation, (New Haven: Yale University Press, 1972 ), p. 12.

${ }^{4}$ William Evan, Organization Theory, (New York: John Wiley, 1976), p. 12.

${ }^{5}$ Melody, pp. 33-55.

${ }^{6}$ Barnouw, pp. 32, 110, and passim.

${ }^{7}$ See for example, Barry Cole and Mal Oettinger, Reluctant Regulators, (Reading, Pennsylvania: Addison-Wesley, 1969); Federal Trade Commission, "FTC Staff Report on Television Advertising to Children" (Washington, DC: Federal Trade Commission, 1978); F. Earle Barcus, Children's Television: An Analysis of Programming and Advertising, (New York: Praeger, 1977); and Geoffrey Cowen, See No Evil: The Backstage Battle Over Sex and Violence on Television, (New York: Simon and Schuster, 1979).

${ }^{8}$ Melody, p. 63.

${ }^{9}$ The coders used the concept of a "television year" in noting the years programs were presented. Taking into account the long-time tendency for the new network season to begin in September, each coder considered a TV year as beginning in September and ending in August. So, for example, a program beginning in October 1977 was listed as part of the 1978 TV year. The coders were trained to use the instrument of analysis prepared for the study, and they were tested for reliability. Using Scott's pi (a conservative index of reliability) the coefficient of reliability was .89. See Ole Holsti, Content Analysis, (Reading, Penn.: Addison-Wesley, 1969).

${ }^{10}$ Anthony Maltese, "Descriptive Study of Children's Programming on Major American Television Networks From 1950 Through 1964,” Ph.D. Dissertation, Ohio University, 1967. Maltese's work actually begins with 1948.

${ }^{11}$ The Nielsen Rating Reports were made available through the kind help of the A.C. Nielsen Company and the Television Information Office Library.

${ }^{12}$ Vincent Terrace ed., The Complete Encyclopedia of Television Programs, (South Brunswick, New Jersey: A.S. Barnes, 1979); and Nina Davis (compiler), The TV Season (Phoenix, Arizona: Oryx Press, annually since 1976).

${ }^{13}$ Clearly, fantasy and reality are impossible to separate completely in any program. The rule guiding the coders was whether the main, continuing premise of the series was or was not within the realm of possibility. Thus, while aspects of "The Flintstones" (the presence of houses and factories, for example) certainly parallel reality, the main premise of the show-a prehistoric civilization with all the modern conveniences-is certainly outside the realm of possibility by contemporary standards.

${ }^{14}$ For example, see Evelyn Sarson (editor), Action For Children's Television, (New York: Avon Books, 1971), and Federal Communications Commission, "Children's Television Report and Policy Statement," Federal Register, 39:215 (November 6, 1974), paragraph 22.

${ }^{15}$ Les Brown, Television: The Business Behind the Box, (New York: Harcourt, Brace, Jovanovich, 1972); Erik Barnouw, The Sponsor, (New York: Oxford, 1978); William Melody, Children's Television: The Economics of Exploitation, (New Haven: Yale University Press, 1972); and Sterling Quinlan, Inside ABC: The American Broadcasting Company's Rise to Power, (New York: Hastings House, 1979).

${ }^{16}$ The author is grateful to William Behanna of the Nielsen Company for this information.

Joseph Turow is an Assistant Professor of Communication at Purdue University. The author acknowledges the assistance of Edward Gain, Maureen Delp, Susan Green and Brian Fontes in carrying out this study. A major portion of the research was conducted under contract to the Federal Communications Commission. (Manuscript accepted January, 1980). 